\title{
Current and future impact of green chemistry on the pharmaceutical industry
}

"The utilization of green chemistry principles in the pharmaceutical industry can be viewed as both an obligation and a significant opportunity to enhance our positive impact on the global community."

In his 1798 publication, An Essay on the Principle of Population, Thomas Robert Malthus hypothesized the principle that the rate of population growth has a tendency to outstrip the capacity to support it [1]. Malthusian catastrophes on a global scale have so far been avoided in our history, yet the patterns of consumption in our industrialized society are unsustainable for future generations. In this regard, I would like to discuss the field of green chemistry (GC), which provides a framework to build sustainability for the chemical industry as a whole. Three corollaries of GC are [2]:

- The designer of a chemical must take into account what will happen after the agent is in widespread use in the marketplace;

- Sustainability coupled with economic advantage is the end objective;

- Industrialized nations are obliged to ensure that access to technological developments is preserved for emerging economies.

The utilization of GC principles in the pharmaceutical industry can therefore be viewed as both an obligation and a significant opportunity to enhance our positive impact on the global community.

The original definition of GC was "the invention, design and application of chemical products and processes to reduce or eliminate the use and generation of hazardous substances" [3]. Sustainability was added shortly after as another fundamental GC concept. In addition, the relationship between GC and developing nations was articulated by the Organization for Economic Cooperation and Development [2]. Paul Anastas and John Warner provided 'the' comprehensive definition of GC in 12 principles [4]. These are to:
- Prevent waste;

- Design safer chemicals and products;

- Design less hazardous chemical syntheses;

- Use renewable feedstocks;

- Use catalysts, not stoichiometric reagents;

- Avoid chemical derivatives;

- Maximize atom economy;

- Use safer solvents and reaction conditions;

- Increase energy efficiency;

- Design chemicals and products to degrade after use;

- Carry out analysis in real time to prevent pollution;

- Minimize the potential for accidents.

The first applications of deliberate 'green' chemical designs are not easy to identify historically, as such. Environmental destruction and the social responsibility of industry were given wide public attention with the publication of Silent Spring by Rachel Carson [5]. The coining of the term 'green chemistry' provided a common banner for existing efforts and emphasized the need to evaluate overall efficiency and minimize waste by design, rather than by segregation and chemical treatment.

\section{Green chemistry organizations \& education}

The US Environmental Protection Agency was an important, early champion of GC with its Presidential Green Chemistry Challenge Awards [101]. GC, however, has always been a truly international effort [102]. The UK, Northern Ireland and The Netherlands have GC efforts with particularly strong collaborations between industry and academia. Italy

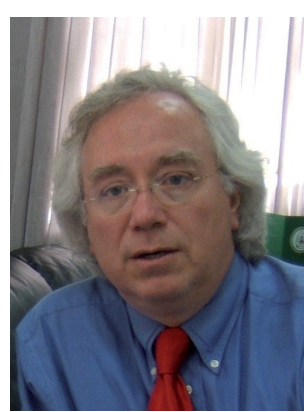

Joseph M Fortunak Department of Chemistry, Howard University, 525 College Street NW, Washington, DC 20059, USA

Tel.: + I 2028066880

Fax: + I 2028065442

E-mail: jfortunak@

comcast.net 
is unique for its important consortium of Universities, Inter-University Consortium "Chemistry for the Environment". Japan is notable for its focus on new technologies and the Green \& Sustainable Energy Network. Brazil has made very important strides in energy production from hydroelectrics and sugar cane. Germany is notable for its emphasis on green solvents and solvent replacements to minimize waste generation during chemical processing.

Education is also important for building sustainability into the thoughts of future scientists, and yet GC is rarely taught to undergraduates. Adding courses on GC into an already-crowded chemistry curriculum is difficult, while most University faculties have never been exposed to the field. General and organic chemistry textbooks mention GC, but this subject matter is not often a part of student assessments. As a result, GC education is often left to individual faculties. Significant resources to develop GC education are, however, now available online. The Royal Society of Chemistry provides a series of interesting Interactive Teaching Units (ITUs) developed by the University of Glasgow, UK [103]; while the American Chemical Society's, Green Chemistry Institute provides GC teaching resources [104]. The University of Oregon, USA, hosts a GC teaching workshop, provides materials on its website and has produced a popular GC organic laboratory manual [105]. Numerous Universities in Australia, Singapore and the UK offer BSc (honors) degrees with a research component in GC, but Cambridge College in Lawrence, MA, USA, offers the only BSc and MSc degrees available that are specifically in GC.

\section{GC in industry}

The value of GC is measured by its commercial uptake, that is, successful examples that yield more efficient processing. Examples of reactions and technologies that have become important in recent years include:

- Continuous processing: flow-through reactors where materials reside for relatively short periods of time can greatly minimize a manufacturing 'footprint' and provide advantages for processing sensitive materials (see for a number of examples [6]);

- Bioengineering and the use of enzymes for selective transformations: Pfizer's atorvastatin side chain process is one such example [106];
- Aqueous hydrogen peroxide or oxygen for oxidations and treatment of waste (see ibuprofenamide as an example [7]);

- The 2005 Nobel prize for Chemistry (Y Chauvin, RR Schrock and RH Grubbs) for metathesis chemistry (consult [8] for details of a ring-closing metathesis reaction carried out on a large scale);

- The 2001 Nobel prize for Chemistry (WS Knowles and R Noyori; chirally catalyzed hydrogenations, and KB Sharpless; chirally catalyzed oxidations);

- 'Quality By Design' [107] and 'Process Analytical Technologies' (PAT) [108] are US FDA initiatives. As a part of 'current Good Manufacturing Practices' (cGMPs) for the 21st Century, these guidelines provide a framework for the introduction of significant new technologies to improve manufacturing efficiency in both active pharmaceutical ingredient (API) and finished dose form processing.

\section{GC in pharma}

The business case for GC in the pharmaceutical industry includes good corporate citizenship, reduced expense, lowered regulatory risk and a smaller environmental footprint. Between three major types of cost, people, fixed or 'sunk' costs, and variable costs of raw materials/energy/time, GC provides immediate impacts on variable cost, although new manufacturing technologies can potentially have a huge impact on fixed cost.

The aproximate US $\$ 70$ million cost of discovering a new chemical entity (NCE) is not greatly reduced by the early application of GC principles. Drug discovery's critical contribution to GC is to design APIs that can be synthesized efficiently as well as providing an 'advance look' to evaluate options for most efficient manufacturing. Potency, selectivity and toxicity are already important discovery issues, although these also qualify as GC.

One thorny problem that is poorly addressed overall is the downstream persistence of drugs and their active metabolites in the environment. The FDA, EMEA and Ministry of Labor, Welfare and Health (MLWH), Japan, require detailed environmental studies that include the potential to harm fish and plant life as part of a marketing application. No truly good tests are available, however, to evaluate the potential for endocrine disruption. Drug discovery, therefore, should ideally add an additional drug selection 
criterion - designing NCEs to rapidly degrade after release to the environment. One GC approach to this issue is improved wastewater treatment to degrade organic materials. This is an important area of research at the Carnegie Mellon Institute for Green Science, PA, USA.

The pharmaceutical industry reported the release of over GB£530 million of chemical waste to the US EPA's Toxic Release Inventory in 2005 [9]. This ranks the industry as the largest user of organic solvents in the USA. API manufacturing generates large volumes of waste because of the length/complexity of syntheses and reactions that are often unsuited to continuous processing. API manufacturing (assuming a six- to eight-step synthetic process) typically generates $25-100 \mathrm{~kg}$ of waste per kilo of drug produced. GlaxoSmithKline (GSK) determined that solvents typically comprise $85-90 \%$ of nonaqueous waste generated by its API processing [10]. By contrast, finished dose production generates much smaller amounts of waste since all ingredients (excepting volatiles) are incorporated into the product and secondary manufacturing requires fewer steps than API production. Secondary manufacturing also utilizes 'generally regarded as safe excipients' (GRAS). For these reasons, I will not discuss finished dose form production (GC discussion on continuous processing for solid dosage forms can be found elsewhere $[109,110])$.

Effective mass yield, environmental (E) factor and atom economy are examples of GC metrics to assess process efficiency. Carbon efficiency (a derivative of effective mass yield) and reaction mass efficiency were developed by GlaxoSmithKline. The ACS's GC Pharmaceutical Roundtable uses a common 'process mass intensity' metric that allows comparison of different API processes [111] to assess their relative degree of 'greenness'.

Approximately 25\% of the US\$897 million development cost for an NCE is related to APIs. Reduced solvent use, enhanced yield/atom economy, continuous processing or PATs often avoid many millions of cost dollars per NCE in Phases II/III. Development is where efficiencies are built in for subsequent commercial production; postapproval changes to manufacturing processes can be implemented, but regulatory hurdles can be a significant barrier to change after commercial launch.

Numerous examples of GC pharmaceutical production exist; the Organic Process Research and Development Journal is a popular place for related publications. The application of biotechnology includes the directed evolution of biocatalysts (by Codexis) for Pfizer's atorvastatin side chain [107] and the bio-engineering of Saccharomyces cerevisiae to produce artemisinic acid for the malaria drug artemisinin (Amyris/Jay Keasling) [11]. Oseltamivir [12] and pelitrexol [13] are also in this category. Pfizer's second-generation synthesis of sertraline [14] and the BASF ibuprofen process are synthetic process examples developed and introduced after commercial launch. GC optimization in Merck's sitagliptin (Januvia) process [101] - which generates no aqueous waste streams - reduced waste by $100 \mathrm{~kg}$ per kilo of drug in comparion with the early-phase synthesis. A supported palladium catalyst for hydrogenation greatly enables the synthesis of the quinolone antibiotic gemifloxacin [15]. The use of olefin metathesis in larger-scale pharmaceutical synthesis has just been published [8], and a challenging application of asymmetric hydrogenation to the synthesis of taranabant has also recently appeared [16]. A second-generation synthesis of pregabalin in which the entire process is run in water is also noteworthy [17].

Green chemistry approaches can safely be said to impact the design of nearly every new API manufacturing process for large pharmaceutical companies. GC technologies that substantially reduce the cost of facilities in the pharmaceutical industry are difficult to publicly document. Continuous processing (process intensification) is underutilized for API manufacturing. Thiaphosgene and diazomethane are generated in continuous processes that are efficient and avoid the accumulation of unsafe concentrations of dangerous reagents. A process reaction, however, must operate at near zero-order kinetics for continuous processing to be an option. Continuous, stirredtank and plug flow reactors have been used in successful commercial applications. Supercritical fluids or ionic liquids as clean solvents that can be recycled, or microwaves as an alternative energy source, are not yet widely applied, but show future promise. Many fine chemical companies (e.g., BASF, Lonza and DSM) have pharmaceutical divisions whose special technologies are utilized heavily by pharmaceutical customers. At this time, however, there does not exist an example of a new API manufacturing plant whose cost has been drastically reduced by the implementation of GC technologies.

The cost of goods manufactured has become a serious concern for most innovator pharmaceutical companies. Manufacturing is estimated 
to be as high as $36-38 \%$ [18] of overall pharmaceutical expense. These surprisingly high numbers indicate an opportunity to enhance corporate competitiveness by reducing manufacturing expense. At the present time, the world is in economic recession. The global expansion that supported the rise of the middle classes in India and China and improvements for much of the rest of the world is in peril. In the USA, healthcare costs were estimated at US\$2.2 trillion (16\% of the gross domestic product) in 2007. Clearly, the USA must reduce healthcare costs as part of handling a budget deficit exceeding US $\$ 1$ trillion. Managing costs will be a major priority for all national and global healthcare strategies in the next decade and pharmaceutical companies must actively participate. GC is important for enabling both sustainability and cost management within the pharmaceutical industry. The application of new technologies and novel synthetic reactions will both play a part in this.

\section{Financial \& competing interests disclosure}

The author has no relevant affiliations or financial involvement with any organization or entity with a financial interest in or financial conflict with the subject matter or materials discussed in the manuscript. This includes employment, consultancies, honoraria, stock ownership or options, expert testimony, grants or patents received or pending, or royalties.

No writing assistance was utilized in the production of this manuscript.

\section{Bibliography}

1 Malthus TR. An Essay on the Principle of Population. Cambridge University Press, Cambridge, UK (1992).

2 Organization for Economic Cooperation and Development. Governance for Sustainable Development: Five OECD Case Studies. 4, 1-345 (2002).

3 Poliakoff M, Fitzpatrick MJ, Farren TR, Anastas PT. Green chemistry, science and the politics of change. Science 298, 807-810 (2002).

4 Anastas PT, Warner JC. Green Chemistry, Theory and Practice. Oxford University Press, NY, USA, 1-19 (1998).

5 Carson RL, Burstyn E, Wilson EO. Silent Spring. 40th Anniversary Edition. Houghton Mifflin Harcourt, Boston, MA, USA (2002).

6 Anderson NG. The impact of process chemists and engineers on green chemistry. Org. Process Res. Dev. 12(6), 1019-1020 (2008).

7 Yadav GD, Leo J. Ceasar kinetics of selective formation of ibuprofenamide by phase transfer catalyzed oxidation of 2-(4-isobutylphenyl) propionitrile with basic hydrogen peroxide. Org. Process Res. Dev. 12(4), 740-747 (2008).

8 Farina V, Shua C, Zheng X et al. Secondgeneration process for the HCV protease inhibitor BILN 2061: a greener approach to ru-catalyzed ring-closing metathesis. $\mathrm{Org}$. Process Res. Dev. 13(2), 250-254 (2009).

9 Slater CS, Savelski M. A method to characterize the greenness of solvents used in pharmaceutical manufacturing. Environ. Sci. Health A Environ. Sci. Eng. Toxic Hazard Subst. Control. 42, 1595-1605 (2007).
10 Constable DJ, Jiminez-Gonzalez C, Henderson RK. Perspective on solvent use in the pharmaceutical industry. Org. Process Res. Dev. 11(1), 133-137 (2007).

11 Ro DK, Paradise EM, Ouellet M et al. Production of the antimalarial drug precursor artemisinic acid in engineered yeast. Nature 440, 940-943 (2006).

12 Harrington PJ, Brown JD, Foderaro T, Hughes RC. Research and development of a second-generation process for oseltamivir phosphate, prodrug for a neuraminidase inhibitor. Org. Process Res. Dev. 8(1), 86-91 (2004).

13 Hu S, Kelly S, Lee S, Tao J, Flahive E. Efficient chemoenzymatic synthesis of pelitrexol via enzymic differentiation of a remote stereocenter. Org. Lett. 8(8), 1653-1655 (2006)

14 Taber GP, Pfisterer DM, Colbert JC. A new and simplified process for preparing $n$-[4-(3,4-dichlorophenyl)-3,4-dihydro-1(2h)naphthalenylidene] methanamine and a telescoped process for the synthesis of (1s-cis)-4-(3,4-dichlorophenol)-1,2,3,4tetrahydro- $n$-methyl-1-naphthalenamine mandelate: key intermediates in the synthesis of sertraline hydrochloride. Org. Process Res. Dev. 8(3), 385-388 (2004).

15 Noh H-K, Lee JS, Kim U et al. Synthesis of the intermediate of gemifloxacin by the chemoselective hydrogenation of 4-cyano-3methoxyimino-1-(n-tert-butoxycarbonyl) pyrrolidine. Part 2: the palladium catalysts in acidic media. Org. Process Res. Dev. 8(5), 788-795 (2006).

16 Wallace DJ, Campos KR, Schultz CS et al. New efficient asymmetric synthesis of taranabant, a cb1r inverse agonist for the treatment of obesity. Org. Process Res. Dev. 13(1), 84-90 (2009).
17 Martinez CA, Hu S, Dumond Y, Tao J, Kelleher P, Tully Y. Development of a chemoenzymatic manufacturing process for pregabalin. Org. Process Res. Dev. 12(3), 392-398 (2008)

18 Scherzer R, Pharma API. The business case for PATs. Presented at: Influencing Change in the Regulatory Environment. API Technical Group 2003 PhRMA API Workshop, Dorado, Puerto Rico, April 28-May 1, 2003.

\section{- Websites}

101 Presidential Green Chemistry Awards www.epa.gov/gcc/pubs/pgcc/presgcc.html (Accessed 1 December 2008)

102 Green Chemistry Institute, International Chapter Affiliates http://portal.acs.org/portal/acs/corg/ content?_nfpb=true \&_pageLabel=PP_ TRANSITIONMAIN\&node id $=1411 \&$ use_sec $=$ false \&sec_url var= region $1 \& \_$_uuid $=49$ ffed $93-$ e $690-426$ c $8252-23 \mathrm{~b} 31431 \mathrm{c} 05 \mathrm{~d}$ (Accessed 2 January 2009)

103 Green chemistry for schools and colleges www.rsc.org/education/teachers/learnnet/ green-chem.htm (Accessed 15 April 2009)

104 ACS Green Chemistry Institute ${ }^{\circledR}$ http://portal.acs.org/portal/acs/corg/ content?_nfpb=true\&_pageLabel=PP TRANSITIONMAIN\&node_id=830\&use_ $\sec =$ false $\&$ sec_url_var $=$ region $1 \&$ _ uuid $=$ acf7b956-d563-4e5d-bacfda49f1c0eca7

(Accessed 15 April 2009)

105 Green Chemistry at the University of Oregon, USA www.uoregon.edu/ -hutchlab/greenchem/ (Accessed 15 April 2009) 
106 Summary of fermentation process, brought about by directed evolution of three biocatalysts www.codexis.com/wt/page/pr_1167522017 (Accessed 23 February 2009)

107 Hussain AS. Pharmaceutical Quality by Design: Improving Emphasis on Manufacturing Science in the 21st Century: www.fda.gov/cder/OPS/PharmQual.pdf (Accessed 2 January 2009)

108 Guidance for Industry PAT - a Framework for Innovative Pharmaceutical

Development, Manufacturing and Quality
Assurance. US Department of Health and Human Services, Food and Drug Administration Center for Drug Evaluation and Research (CDER), Center for Vetrinary Medicines (CVM), Office of Regulatory Affairs (ORA), September, 2004 www.fda.gov/cder/guidance/6419fnl.pdf (Accessed 18 December 2008)

109 Mollan MJ, Lodaya M. Continuous Processing in Pharmaceutical Manufacturing www.ieor.berkeley.edu/ -shen/ieor298/pdd/
110 Continuous processing of solid dosage forms; FDA

www.pharmpro.com/ShowPR.aspx?PUBCO $\mathrm{DE}=021 \& \mathrm{ACCT}=0000100 \& \mathrm{ISSUE}=0601$ $\&$ RELTYPE $=$ PR $\&$ ORIGRELTYPE $=$ ATO $\&$ PRODCODE $=0000 \&$ PRODLETT $=A \& C$ ommonCount $=0$

(Accessed 9 February 2009)

111 Henderson RK, Kindervater J, Manley JB. Lessons Learned through Measuring Green Chemistry Performance - the Pharmaceutical Experience

http://portal.acs.org/portal/fileFetch/C/ CTP_005585/pdf/CTP_005585.pdf (Accessed 23 February 2009) 